\title{
Family Functioning dan Loneliness pada Remaja dengan Orang Tua Tunggal
}

\author{
Diana Savitri Hidayati ${ }^{1}$ \\ ${ }^{1}$ Fakultas Psikologi, Universitas Muhammadiyah Malang \\ e-mail: dianasavitri@umm.ac.id ${ }^{1}$
}

\begin{abstract}
Abstrak. Perubahan struktur keluarga pada keluarga dengan orang tua tunggal akibat perceraian sedikit banyak akan mempengaruhi family functioning keluarga tersebut. Kondisi family functioning tersebut diduga mempunyai korelasi dengan terjadinya loneliness pada remaja sebagai salah satu anggota keluarga dari keluarga dengan orang tua tunggal. Tujuan dari penelitian ini adalah mengetahui hubungan antara family functioning dan loneliness pada remaja dengan orang tua tunggal. Penelitian ini merupakan penelitian kuantitatif korelasional dengan subyek penelitiannya berjumlah 106 remaja berusia 15-18 tahun yang tinggal dengan orang tua tunggal karena perceraian. Metode pengumpulan data melalui skala yaitu skala Family Asessment Device (FAD) dan $R$-UCLA Loneliness Scale yang masing-masing telah diterjemahkan ke Bahasa Indonesia dan telah melalui uji validasi. Hasil penelitian menyatakan bahwa hipotesa penelitian yang diajukan diterima yang berarti bahwa ada hubungan negatif antara family functioning dan loneliness yang dibuktikan oleh perhitungan statistik dengan nilai signifikansi (p) sebesar 0,038.
\end{abstract}

\section{Kata kunci: Family Functioning, Loneliness}

Abstract. When parents get divorced, so there will be a change into a family functioning of this new family. A family functioning will be predicted to rise loneliness in a teenage. The aim of this study is to determine the relationships of family functioning and loneliness in teenage who live with singgle parents after divorced. Methode research is a quantitative approach to correlation with number of subjects were 106 teenage who 15-18 years old. Methode of data collecting in this study by Family Asessment Device (FAD) and R-UCLA loneliness scale. The results showed that there is a significant correlations between family functioning and loneliness $(r=-0.202 ; p=0.038$; Correlation is significant at the 0,05 level).

Keywords: Family Functioning, Loneliness

Penelitian Parlee (dalam Sears, Fredman \& Peplau, 2009) menyebutkan bahwa dari 40.000 individu yang merasakan loneliness, $79 \%$ diantaranya berusia remaja. Sejalan dengan penelitian tersebut Survey tentang kondisi loneliness di Inggris yang dilaksanakan oleh Mental Health Foundation pada pertengahan tahun 2010, diperoleh data bahwa dari 2256 subyek penelitian : 24\% diantaranya merasakan loneliness, dimana individu berumur 18-34 tahun lebih tinggi tingkat lonelinessnya daripada subyek berumur di atas 55 tahun (Mental Health Foundation, 2010). Berdasarkan penelitian- 
penelitian tersebut dapat disimpulkan bahwa loneliness terjadi juga pada usia remaja, bahkan jumlah remaja yang mengalami kesepian lebih besar daripada usia dewasa.

Berdasarkan penelitian Ernst dan Cacioppo (1999) diperoleh informasi bahwa loneliness yang kronis terjadi karena pengalaman awal masa kecil yang negatif terutama proses kelekatan awal terhadap figur lekat anak yaitu ibu. Uruk dan Demir (2003) dalam penelitiannya tentang faktor-faktor yang melatarbelakangi terjadinya loneliness pada remaja di kota Ankara Turki, menyimpulkan bahwa faktor keluarga menjadi penyebab kedua terbesar dari loneliness yang dialami oleh subyek penelitian. Sejalan dengan penelitian tersebut, Gürsoy dan Biçakçi (2006) dalam penelitiannya menyebutkan bahwa perbedaan tingkat kesepian yang terjadi pada remaja dipengaruhi oleh perbedaan status ekonomi, kualitas hubungan antar anggota keluarga dan kualitas hubungan pertemanan. Berdasarkan fakta-fakta tersebut dapat disimpulkan bahwa loneliness pada remaja dilatarbelakangi oleh kondisi keluarga dimana remaja yang bersangkutan tinggal. Kondisi keluarga yang dimaksud di sini lebih difokuskan lagi pada keberfungsian keluarga atau family functioning.

Menurut Openshaw (2011) keberfungsian keluarga atau family functioning pada prinsipnya mengacu pada kualitas interaksi antar anggota keluarga, yaitu cara mereka bersosialisasi secara positif antar anggota keluarga. Stewart (1992) mempunyai pendapat yang lebih kompleks mengenai family functioning, yang muncul sebagai konsep mengenai : karakteristik keluarga, kemampuan menyesuaikan diri, komunikasi, self acceptance, dukungan sosial, kasih sayang, waktu yang diluangkan bersama-sama, kemampuan meneekspresikan emosi, problem solving, moralitas atau religiusitas, iklim keluarga, kebencian dan keperdulian antar masing-masing anggota keluarga.

Sementara itu family functioning pada keluarga yang orang tuanya telah bercerai pasti akan mengalami perubahan karena adanya perubahan pada struktur keluarga menjadi keluarga dengan orang tua tunggal yaitu ayah atau ibu saja. Kisworowati (2010) menyebutkan bahwa orang tua tunggal karena perceraian harus menyesuaikan diri dengan tugas barunya sebagai pemimpin keluarga sekaligus sebagai pengurus rumah tangga dan tetap harus memenuhi kebutuhan rumah tangga. Dalam kondisi tersebut ibu atau ayah sebagai orang tua tunggal menyesuaikan diri dengan proses pengolahan sistem keluarga, mempertahankan standart keluarga dan pengaturan keuangan keluarga yang merupakan bagian dari keberfungsian keluarga.

Fakta lain mengatakan bahwa pasca perceraian orang tuanya, kemungkinan remaja akan mengalami dampak psikologis dimana salah satunya adalah kesepian. Hal ini sesuai dengan pendapat Wasil (2014) yang menyatakan bahwa perceraian memiliki dampak psikologis pada anak seperti : merasa tidak nyaman karena kehilangan salah satu anggota keluarganya, emosi yang tidak stabil seperti rasa marah, merasa kesepian karena hilangnya salah satu anggota keluarga, rasa sedih dan rasa kecewa terhadap keluarganya.

Peneliti mencoba mengaitkan fenomena tersebut, bagaimana kesepian terjadi pada remaja setelah tinggal hanya dengan ayah atau ibunya saja setelah perceraian orang tuanya. Perasaan kesepian tersebut sangat mungkin terjadi karena komunikasi dan interaksi antar anggota keluarga yang tidak berjalan dengan baik karena adanya 
perubahan pada struktur keluarga. Kualitas komunikasi dan interaksi dalam keluarga mengacu pada konsep family fuctioning.

Penelitian sebelumnya mengenai keberfungsian keluarga dan kesepian pada remaja menyimpulkan bahwa ada hubungan negatif antara keberfungsian keluarga dan kesepian. Hal ini berarti bahwa semakin positif keberfungsian keluarga maka semakin rendah kesepian yang dirasakan remaja (Cendra,2012).

Berdasarakan uraian-uraian sebelumnya, maka peneliti tertarik untuk melaksanakn penelitian untuk mengetahui hubungan antara family functioning dan loneliness pada remaja dengan orang tua tunggal. Adapun perbedaan penelitian ini dengan penelitian terdahulu adalah karakteristik subyek penelitian yang tinggal dengan orang tua tunggal karena perceraian. Manfaat dari penelitian ini adalah diharapkan mampu memberi informasi tambahan tentang family functioning dan loneliness. Hipotesa penelitian ini adalah ada hubungan negatif antara family functioning dengan loneliness. Semakin positif family functioning maka semakin rendah loneliness yang dirasakan oleh subyek penelitian.

\section{METODE}

Rancangan penelitian dalam penelitian ini adalah penelitian kuantitatif korelasional yang bertujuan untuk mengetahui hubungan antara dua variabel yakni keberfungsian keluarga dan loneliness pada remaja yang tinggal dengan orang tua tunggal karena perceraian. Subjek dalam penelitian ini adalah remaja baik laki-laki dan perempuan, dengan usia 15 - 18 tahun, saat ini sedang tinggal dengan orang tua tunggal (ayah atau ibu) karena perceraian orang tuanya dan usia.perceraian orang tuanya sudah lebih dari 5 tahun. Jumlah subyek dalam penelitian adalah 106 remaja. Teknik sampling yang digunakan adalah non-probability sampling yaitu purposive sampling dan snowball sampling, dimana subjek penelitian ini tidak diambil secara acak namun subjek dipilih sesuai dengan kriteria yang telah ditentukan sebelumnya sehingga benar-benar sesuai dengan tujuan penelitian ini dan peneliti mendapat informasi tentang keberadaan subyek penelitian lain dari subyek penelitian yang telah bersedia berpartisipasi sebelumnya.

Penelitian ini memiliki dua variabel, yaitu variabel bebas dan variabel terikat.Variabel bebas dalam penelitian ini adalah family functioning dan variabel terikatnya adalah loneliness. Family functioning adalah suatu keadaan di dalam keluarga yang mampu membentuk anggota keluarganya menjadi pribadi yang positif atau negatif dengan menjalin komunikasi secara efektif serta memberikan dukungan dan mengembangkan nilai-nilai atau norma di dalam keluarga dan lingkungan masyarakat. Instrumen yang digunakan untuk mengukur family functioning adalah Family Asessment Device (FAD) yang disusun oleh Epstein, Baldwin, dan Bishop (1983) yang telah diterjemahkan ke dalam Bahasa Indonesia. Skala family functioning berdasarkan aspek-aspek: (1) Pemecahan masalah, (2) Komunikasi, (3) Peranan keluarga, (4) Responsivitas afektif, (5) Keterlibatan afektif, (6) Kontrol perilaku, dan (7) Fungsi umum. Jenis skala dalam 
instrumen ini adalah skala likert. Indeks validitas berkisar antara 0,322 - 0,759 dan reliabilitas sebesar 0,95 (Sulanjono, 2016).

Loneliness adalah reaksi emosional dan kognitif seseorang pada suatu peristiwa yang tidak menyenangkan yaitu penurunan kualitas dan kuantitas hubungan sosialnya. Instrumen penelitian untuk mengukur loneliness adalah skala Loneliness yang disusun oleh Russel (1996) yaitu Revised University of California, Los Angeles Loneliness Scale ( $R$-UCLA Loneliness Scale) versi 3 yang telah diterjemahkan ke dalam Bahasa Indonesia. Jenis skala dari instrumen ini adalah Likert dengan 4 pilihan jawaban yaitu Tidak Pernah, Jarang, Kadang-kadang, dan Selalu. Jumlah item sebanyak 20, yang terdiri dari 11 item negatif (kesepian) dan 9 item positif (tidak kesepian), sementara indeks validitas dari skala ini adalah 0,320-0,658 dengan reliabilitas 0,883 (Nurlayli \& Hidayati, 2014).

Pengolahan data sekaligus proses analisa data melalui teknik korelasi product moment dari Pearson dengan bantuan SPSS for Windows 20 yang bertujuan untuk mengetahui hubungan antara variabel dependen yaitu loneliness dan variabel independent yaitu family functioning.

\section{HASIL}

Tabel 1.

Hubungan Family functioning dan Loneliness

\begin{tabular}{lcccc}
\hline \multicolumn{1}{c}{ Variabel } & $\mathbf{R}$ & $\mathbf{S i g}(\mathbf{p})$ & $\mathbf{r}^{\mathbf{2}}$ \\
\hline $\begin{array}{l}\text { Family functioning } \\
\text { Loneliness }\end{array}$ & dan & $-0,202$ & 0,038 & 0,04 \\
\hline
\end{tabular}

*Korelasi signifikan pada 0,05

Berdasarkan analisa data melalui uji Pearson Product Moment, diperoleh informasi bahwa ada hubungan antara variabel Family functionings dan Loneliness dengan nilai $\mathrm{p}=$ 0,038 . Hal tersebut menunjukkan bahwa kedua variabel memiliki hubungan yang signifikan karena nilai $\mathrm{p}<0,05$. Arah hubungan dari kedua variabel menunjukkan hubungan negatif $(\mathrm{R}=-0,202)$ yang artinya semakin positif family functioning maka semakin rendah loneliness, begitu juga sebaliknya yaitu semakin negatif family functioning, maka semakin tinggi loneliness. Selain itu diperoleh informasi juga bahwa family functioning memberikan kontribusi sebesar $4 \%$ terhadap tingkat loneliness seseorang $\left(r^{2}=0,04\right)$.

\section{DISKUSI}

Hasil penelitian menyatakan bahwa terdapat hubungan negatif yang signifikan antara family functioning dan loneliness, dimana ini berarti bahwa semakin positif family functioning yang dirasakan maka semakin rendah loneliness yang dirasakan subyek penelitian, dan sebaliknya semakin negatif family functioning yang dirasakan maka 
semakin tinggi loneliness yang dirasakan oleh subyek penelitian. Lebih jauh hal tersebut berarti bahwa hipotesa penelitian yang diajukan oleh peneliti diterima.

Hasil penelitian ini didukung oleh hasil penelitian terdahulu dengan variabel yang sama oleh Cendra (2012) dan penelitian yang hampir sama yaitu tentang keterkaitan kondisi keluarga dengan loneliness oleh Uruk dan Demir (2003) dan Gürsoy dan Biçakçi (2006). Lebih jauh Gürsoy dan Biçakçi (2006) menjelaskan bahwa hubungan positif antar anggota keluarga dan dukungan yang kuat dari orang tua penting bagi terbentuknya kesejahteraan remaja. Komunikasi yang tidak efektif antar anggota keluarga dan ketidakmampuan mendiskusikan masalah dalam keluarga akan membuat remaja merasakan kesepian.

Beberapa bagian dalam family functioning seperti : karakteristik keluarga, kemampuan menyesuaikan diri, komunikasi, self acceptance, dukungan sosial, kasih sayang, waktu yang diluangkan bersama-sama, kemampuan mengekspresikan emosi, problem solving, moralitas atau religiusitas, iklim keluarga, kebencian dan keperdulian antara masingmasing anggota keluarga mempunyai korelasi terhadap munculnya kesepian pada anggota keluarga. Menurut DeGenova (2008), interaksi yang tidak efektif antar anggota keluarga bisa mengakibatkan kesepian pada anggota keluarga tersebut. Sementara Brennan (1982) menegaskan bahwa hubungan orang tua dan anak yang buruk menjadi prediktor munculnya kesepian pada remaja. Pendapat lain dari Russel, Cutrona, Rose dan Yurko (dalam Bednar, 2000) menyatakan bahwa emotional loneliness berkaitan dengan minimnya kedekatan dengan orang di sekitarnya, dimana bagi remaja lingkungan sekitarnya yang utama adalah lingkungan keluarga.

Menurut McMaster Model Of Family Functioning (Epstein dkk, 1983) salah satu dimensi dalam family functioning yang berkontribusi terhadap kemunculan loneliness pada remaja adalah dimensi komunikasi. Lebih jauh dijelaskan bahwa kesediaan orangtua untuk menerima, mendengar, dan menyayangi anak-anaknya akan membentuk situasi yang kondusif untuk anak agar mau berkomunikasi dengan anggota keluarga yang lain. Kondisi tersebut tentu saja akan membuat anak tidak merasa kesepian. Selanjutnya kebiasaan berkomunikasi yang disampaikan secara jelas dan langsung di dalam keluarga, akan membuat anak terampil berkomunikasi dengan orang lain di luar keluarga sehingga semakin tidak kesepian.

Subyek penelitian merupakan remaja yang tinggal dengan orang tua tunggal yaitu ayah atau ibu saja karena perceraian. Kondisi pasca perceraian orang tuanya bisa membuat remaja merasakan kesedihan, namun demikian struktur keluarga yang kondusif mempunyai peran dalam membantu remaja agar tidak terus merasakan kesedihan dan mengubah pemahaman terhadap konflik keluarga yang telah terjadi menjadi pengalaman masa lalu yang bernilai positif sekaligus sebagai sebuah pembelajaran pada masa depan (Primasti dan Wrastari, 2013). Namun demikian pada keluarga bercerai sering kali terjadi kualitas hubungan orangtua dan anak yang rendah karena kurangnya kehangatan, dukungan, interaksi dan komunikasi serta konflik orang tua karena perceraian (Mooney, Oliver \& Smith, 2009). Rendahnya kualitas hubungan orangtua dan anak ini bisa menjadi prediktor dari loneliness. Perlman dan Peplau (1998) menyatakan bahwa kualitas 
hubungan seseorang menjadi prediktor yang lebih kuat terhadap terjadinya loneliness dibandingkan dengan kuantitas hubungan atau jumlah teman yang dimiliki

Weiss (dalam Perlman dan Peplau, 1998) membagi loneliness menjadi dua, yaitu emotional loneliness dan social loneliness. Hidayati (2016) menyatakan pendapatnya bahwa emotional loneliness mengacu pada emosi negatif yang muncul akibat ketidakpuasan pada hubungan yang bersifat intim, dimana hubungan intim yang dimaksud adalah hubungan dengan figur attachment anak yaitu ayah atau ibunya. Oleh karena itu peneliti menganggap bahwa loneliness yang dirasakan oleh subyek penelitian kemungkinan adalah emotional loneliness karena terjadi akibat dari jarangnya berinteraksi dengan anggota keluarganya yang lain.

Berdasarkan sudut pandang budaya, maka tugas perkembangan remaja di negara dengan kebudayaan timur seperti Indonesia berbeda dengan tugas perkembangan remaja di negara barat. Sebagai negara dengan kebudayaan timur, maka budaya yang dianut adalah kolektivism sehingga salah tugas perkembangan remajanya adalah menyatukan diri dengan keluarga (Sawir dkk, 2007). Hal ini senada dengan pendapat Papalia dkk (2009) bahwa remaja di negara timur akan menghabiskan waktu lebih banyak bersama keluarga dibandingkan remaja di negara barat. Oleh karena itu peneliti menyimpulkan bahwa kesepian remaja di negara timur akan lebih besar kemungkinan terjadinya jika remaja yang bersangkutan tidak mengalami hubungan yang mendalam dengan anggota keluarganya.

Keterbatasan penelitian ini terletak pada jumlah subyek penelitian yang hanya 106 orang remaja yang tinggal dengan orangtua tunggal berusia 15-18 tahun. Kondisi ini terjadi karena terbatasnya remaja yang memenuhi karakter sebagai subyek penelitian yang bersedia terlibat dalam penelitian ini. Selain itu, keterbatasan lain penelitian ini adalah peneliti belum mendeskripsikan korelasi loneliness subyek penelitian berdasarkan dimensi-dimensi dalam family functioning sehingga belum diketahui dimensi apa dalam family functioning yang mempunyai kontribusi terbesar terhadap munculnya loneliness remaja yang tingga dengan orang tua tunggal.

\section{SIMPULAN DAN IMPLIKASI}

Berdasarkan hasil penelitian ini diperoleh hasil bahwa hipotesa penelitian yang diajukan diterima, dimana ini berarti bahwa ada hubungan negatif yang signifikan antara family functioning dan loneliness. Ini dibuktikan oleh perhitungan statistik dengan nilai signifikansi (p) yaitu 0.038 nilai $\mathrm{R}=-0,202$. Family functioning memberikan kontribusi sebesar $4 \%$ terhadap munculnya loneliness pada subyek penelitian $\left(\mathrm{r}^{2}=0,04\right)$, yang artinya sebesar $96 \%$ faktor lain berkontribusi terhadap munculnya loneliness.

Implikasi untuk remaja khususnya subyek penelitian agar berusaha menjalin komunikasi dan interaksi dengan anggota keluarga baik itu ayah atau ibu, kakak atau adik serta anggota keluarga yang lain yang saat ini tinggal satu rumah agar tidak merasa kesepian; misalnya dengan meluangkan waktu lebih banyak bersama keluarga dan menjadikan keluarga sebagai tempat utama untuk berbagi. Bagi orang tua tunggal baik ayah atau ibu 
sebaiknya tetap bisa mengatur perannya sebagai pemimpin rumah tangga, pengatur rumah tangga sekaligus sebagai sumber ekonomi agar bisa menjalankan peranya dengan seimbang sehinggadiharapkan tidak banyak konflik karena adanya perubahan struktur keluarga setelah adanya perceraian.

Implikasi untuk peneliti selanjutnya yang tertarik dengan tema yang sama diharapkan untuk menganalisa lebih dalam tentang dimensi-dimensi dalam variabel family functioning sehingga bisa diketahui prediktor terbesar yang menyebabkan munculnya loneliness.

\section{REFERENSI}

Baron, R. A., \& Byrne, D. (2005). Psikologi sosial edisi kesepuluh. Jakarta: Erlangga

Bednar, K.L. (2000). Loneliness and self-esteem at different levels of the self. Honor project psychology, digital commons @ IWU. Illinois Wesleyan University

Brennan, T. (1982). Loneliness at adolescence.In L.A. Peplau \& D. Perlman (eds). Loneliness : A sourcebookof current theory, research, and therapy (pp. 269-290). New York : wiley-Interscience.

Cendra, A., (2012). Hubungan antara keberfungsian keluarga dan kesepian pada remaja indonesia. Skripsi Sarjana Psikologi. Fakultas Psikologi Universitas Indonesia

Epstein, N.B., Baldwin, L., \& Bishop, D.S. (1983). The mc master family assesment device. Journal of Marital and Family Therapy 1983, 9(2), 171-180

Ernst, J.M. and Cacioppo, J.T. (1999). Lonely hearts : psychological perspectives on loneliness. Applied \& Preventive Psychology. 8:1-22. USA: Cambridge University Press

Fahrudin, A. (2012). Keberfungsian keluarga: konsep dan indikator pengukuran dalam penelitian. Jurnal Informasi, 17(02)

Gürsoy, F., \& Biçakçi, M.Y.,(2006). A study on the loneliness level of adolescents. Journal of qafqaz university number 18, 140-146. Ankara-Turkiye

Hidayati, D.S. (2016). Shyness dan loneliness. Proceeding seminar ASEAN $2^{\text {nd }}$. Malang : Program Pasca Sarjana Psikologi Universitas Muhammadiyah Malang

Kisworowati, N. (2010). Strategi coping ibu dalam menjalani peran sebagai orang tua tunggal. Skripsi Sarjana Psikologi. Fakultas Psikologi Universitas Muhammadiyah Surakarta

Lake,T.(1986). Kesepian. Jakarta: Arcan 
Mental Health Foundation. (2010). The Mental Health Foundation survey. Laporan Penelitian, Mental Health Foundation. Mental Health Foundation. (2010). The lonely society?, 2010. Inggris: Mental Health Foundation.

Miller, I. W., Ryan, C., Keitner, G., Bishop D. \& Epstein N. (2000). The mcmaster approach to families : theory, assesment, treatment and research. Journal of Family Therapy, 22, 168-189

Mooney, A., Oliver, C. \& Smith, M. (2009). Impact of family breakdown on children's well-being. Institute of Education, University of London

Nurlayli, R.K. \& Hidayati, D.S. (2014). Kesepian pemilik hewan peliharaan yang tinggal terpisah dari keluarga. Jurnal Ilmiah Psikologi Terapan, 2 (1), 21-35

Openshaw, K. P. (2011). The relationship between family functioning, family resilience, and quality of life among vocational rehabilitation clients. Utah : Utah State University

Papalia,D.E., Olds, S.W., and Feldman, R.D.(2009). Human development (1 $1^{\text {th }}$ ed.). New York : McGraw - Hill Companies Inc.

Perlman, D., \& Peplau, L. A. (1998). Loneliness. In H. S. Friedman (Ed.) Encyclopedia of mental health, Vol 2 (571-581). San Diego, CA: Academic Press

Primasti, K. \& Wrastari A. (2013).Dinamika psychological wellbeing pada remaja yang mengalami perceraian orangtua ditinjau dari family confict yang dialami. Jurnal Psikologi Kepribadian dan Sosial 02(03)

Russel, D. W. (1996). UCLA loneliness scale (version 3): reliability, validity, and factor structure. Journal of Personality Assessment, 66, 20-40.

Sanson, A., Brian, B., \& Carol, E. (2010). Positive family functioning. Access Economics Pty Limited.

Sawir, E., Marginson, S., Deumert, A., Nyland, C., \& Ramia, G. (2007). Loneliness and international students : An australian study. Journal of Studies in International Education, 20 (10), 1-33.

Sears, D.O., Fredman, J.L., \& Peplau,L.A. (2009). Psikologi sosial jilid 2. Jakarta : Erlangga.

Stewart, A. L. (1992). Measuring functioning and well-being: the medical outcomes study approach. Duke University Press.

Sulanjono, G.K., (2016). Hubungan keberfungsian keluarga dan kesejahteraan psikologis pada remaja keluarga bercerai. Skripsi Sarjana Psikologi. Fakultas Psikologi Universitas Muhammadiyah Malang.

Tassin, J.M., (1999). Integrating self-concept theory into a model of loneliness. Honor project psychology, digital commons @ IWU. Illinois Wesleyan University. 
Uruk, A.C. and Demir, A., (2003). The role of peers and families in predicting the loneliness level of adolescents. Journal Psychology, Mar;137(2):179-93.

Wasil, S. K. W. (2014). Kondisi psikologi anak dari keluarga yang bercerai. Artikel Ilmiah Hasil Penelitian Mahasiswa Universitas Jember. 